\title{
Dipolar bent and linear acetylenes substituted by cationic quinolinium and anionic benzoates. Formation of mesomeric betaines.
}

\author{
Andreas Schmidt, ${ }^{*}$ Sviatoslav Batsyts, Alexey Smeyanov, \\ Tyll Freese, Eike G. Hübner \\ Clausthal University of Technology, Institute of Organic Chemistry, Leibnizstrasse 6, \\ D-38678 Clausthal-Zellerfeld, Germany.

\section{Martin Nieger} \\ University of Helsinki, Department of Chemistry, Laboratory of Inorganic Chemistry, \\ P.O. Box 55, FIN-00014 University of Helsinki, Finland.
}

1. Frontier orbital profiles ........ 1

2. Thermal ellipsoid plots ........ 2

3. NMR spectra................. 6

4. Calculations.................. 20 


\section{Frontier orbital profiles}
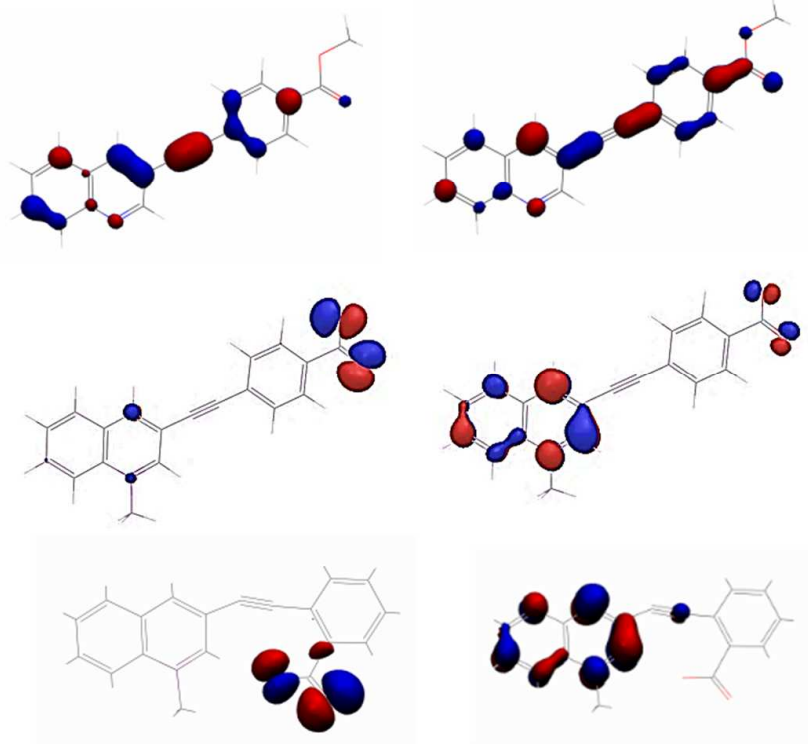

Figure S1. Highest occupied molecular orbitals (HOMOs; left) and lowest unoccupied molecular orbitals (LUMOs; right) of the ester $\mathbf{5 a}$ (above), the mesomeric betaine $\mathbf{8 a}$ (middle), and the instable betaine $\mathbf{8} \mathbf{c}_{\text {bent }}$ (below).
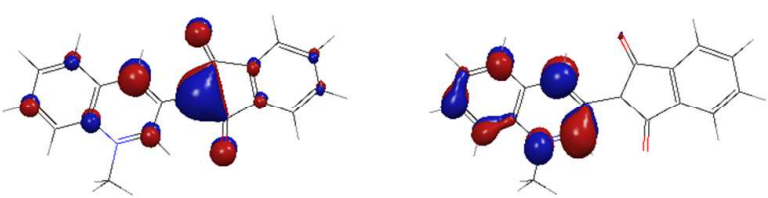

Figure S2. Highest occupied molecular orbital (HOMO, left) and lowest unoccupied molecular orbital (LUMO, right) of mesomeric betaine 10. 


\section{Thermal ellipsoid plots}

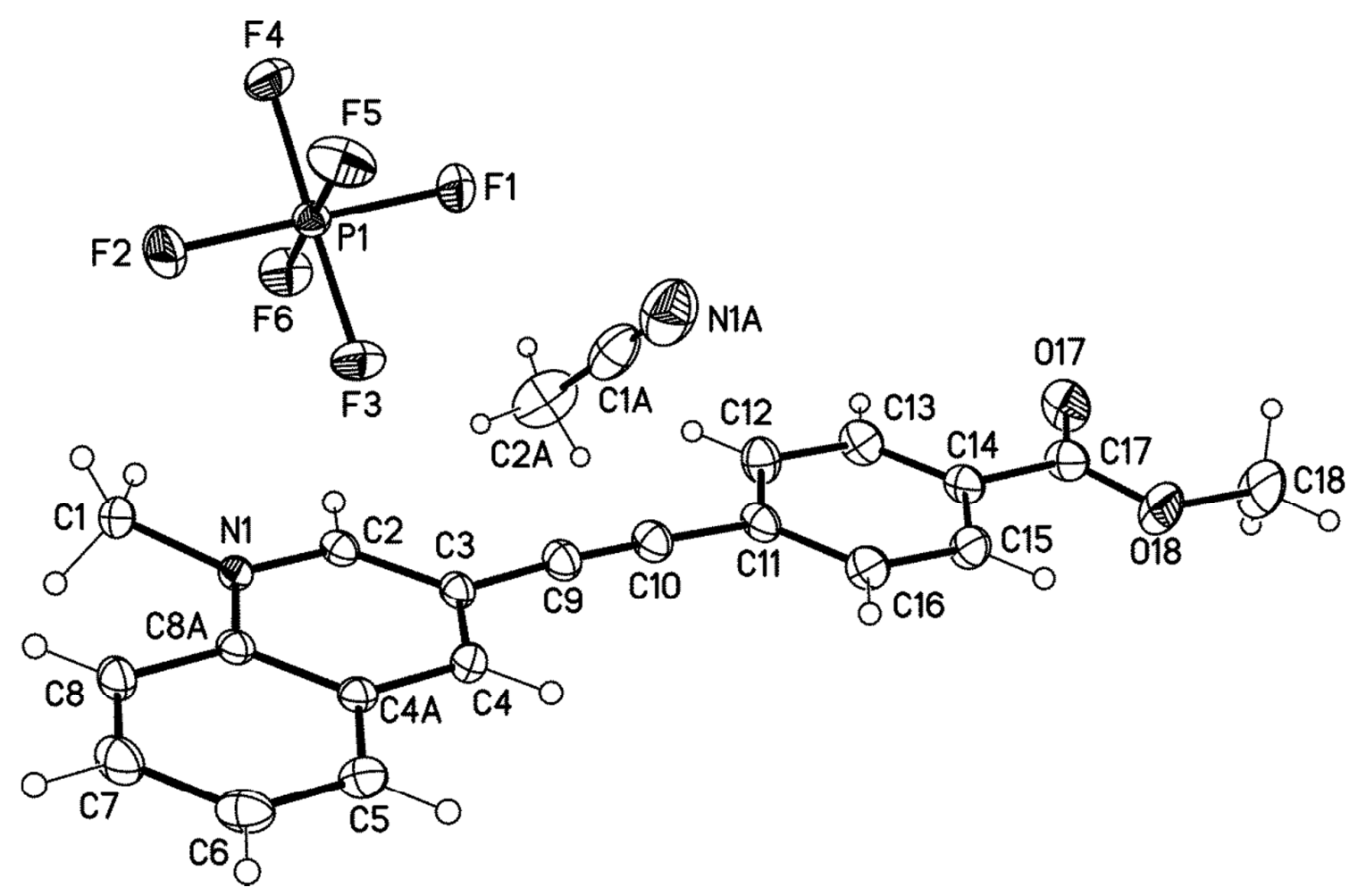

Figure S3. Molecular structure of $\mathbf{6 a}$ (displacement parameters are drawn at $50 \%$ probability level).

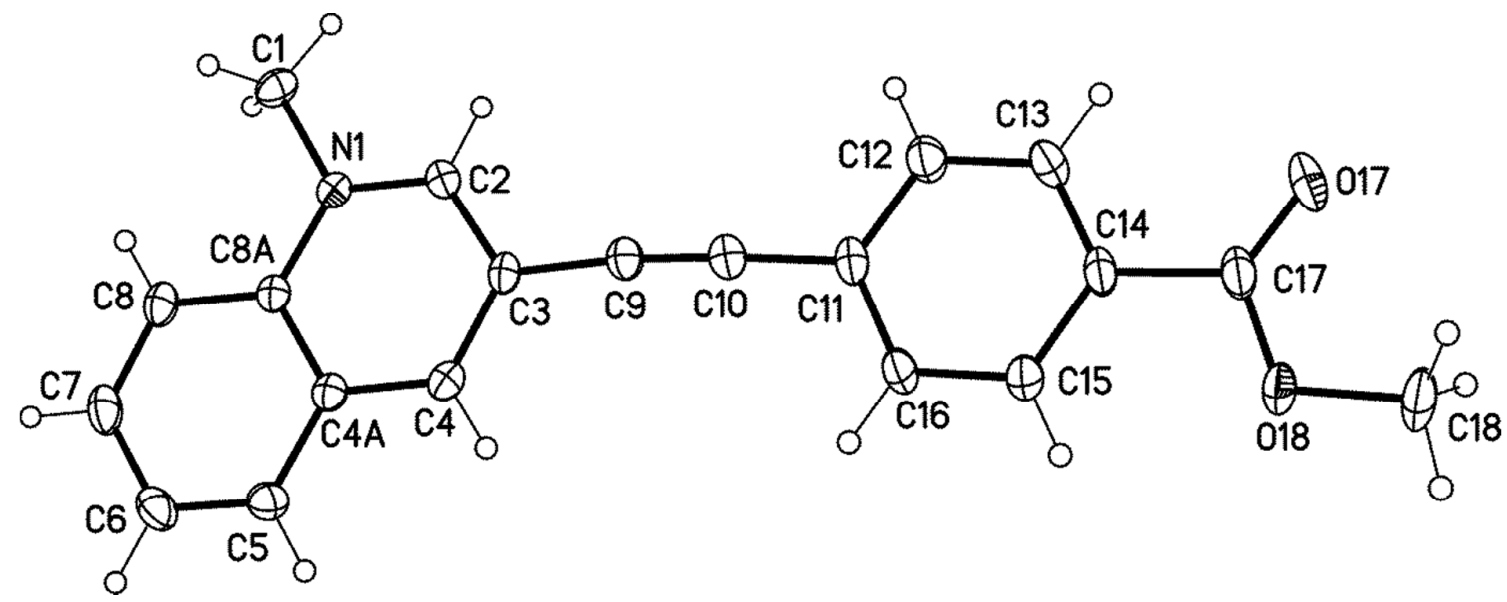

Figure S4. Molecular structure of $\mathbf{6 a}$ (displacement parameters are drawn at $50 \%$ probability level). The anion and $\mathrm{MeCN}$ are omitted for clarity. 


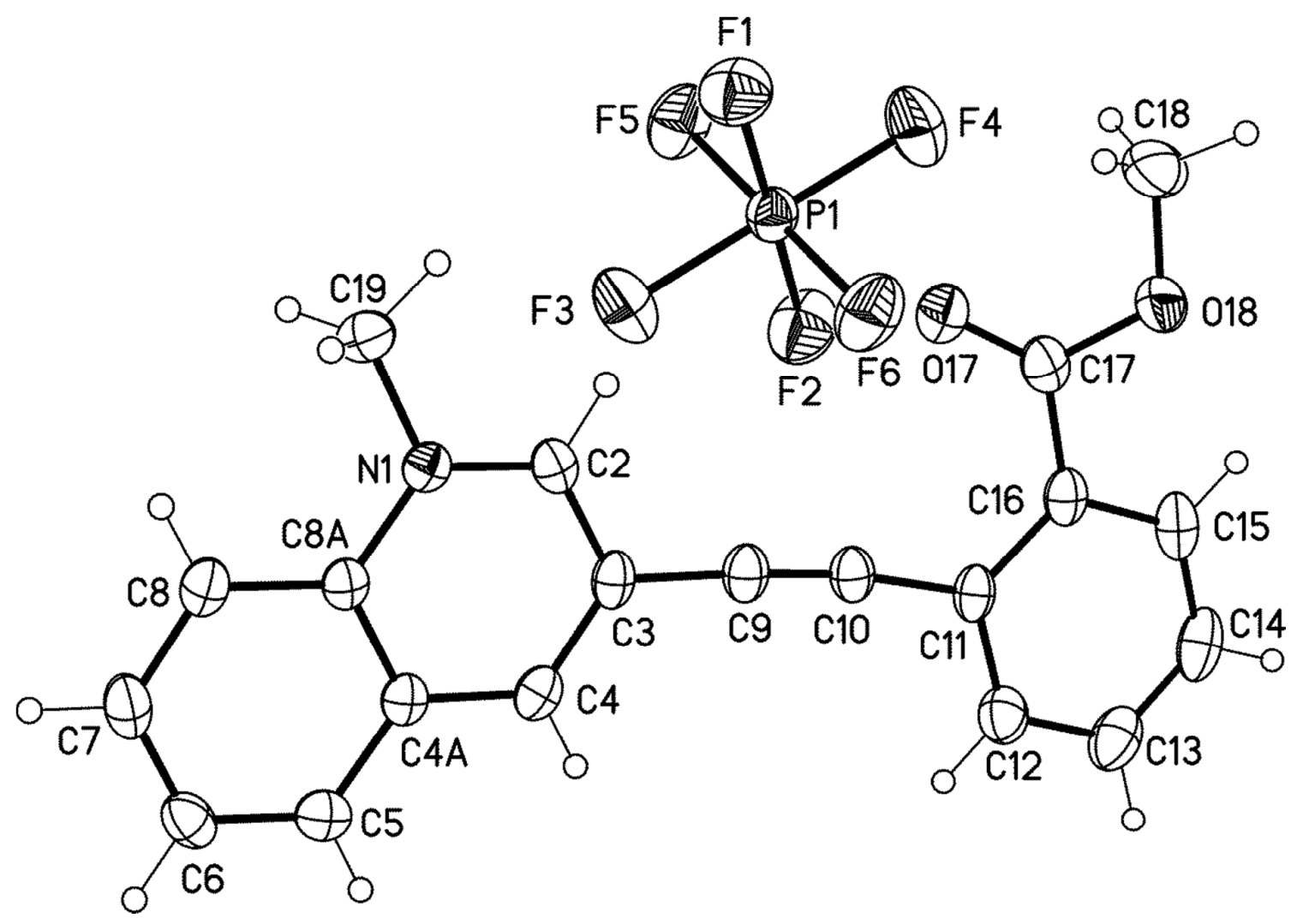

Figure S5. Molecular structure of 6c (displacement parameters are drawn at $50 \%$ probability level). 

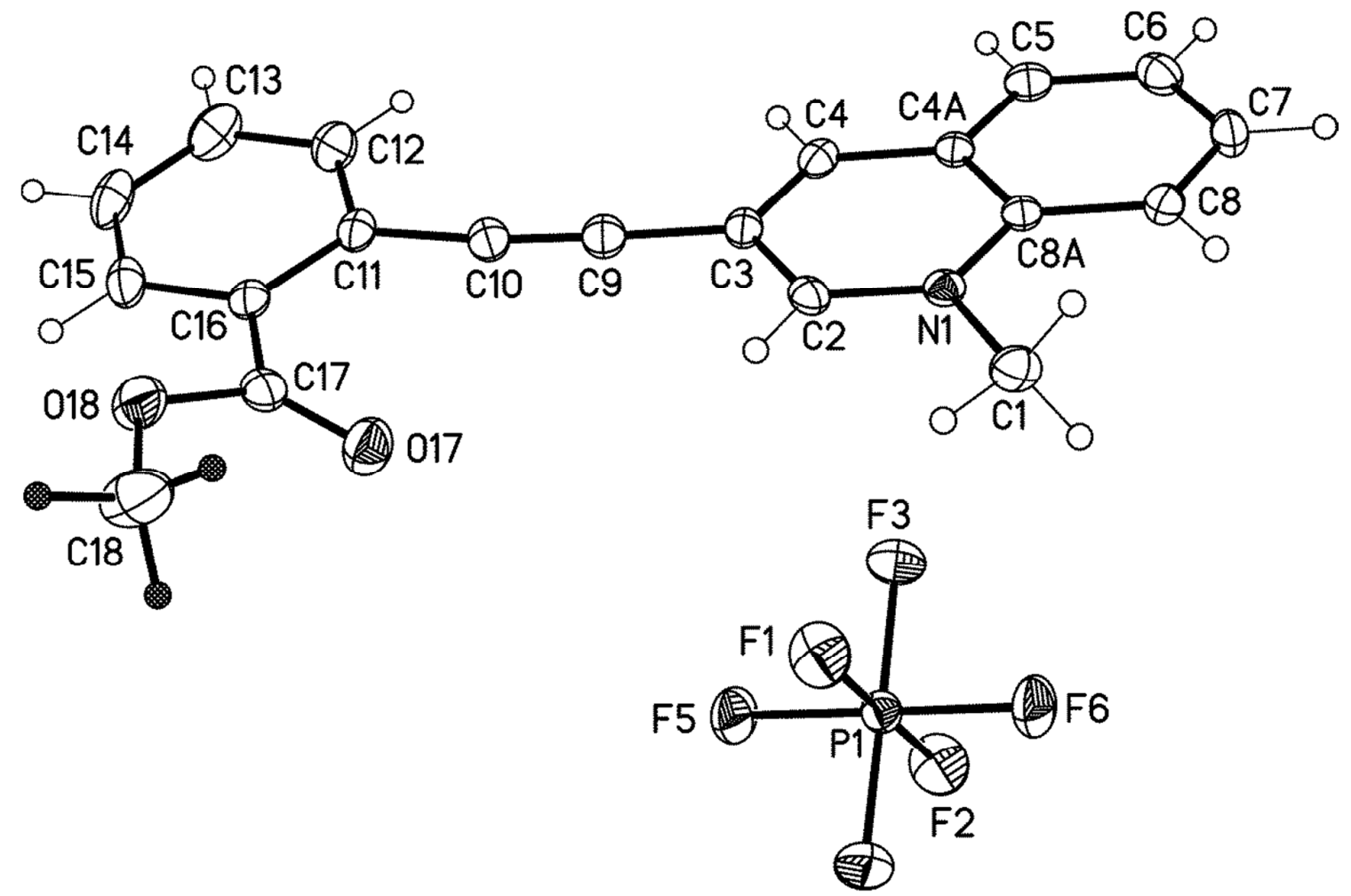

F4

Figure S6. Molecular structure of 6c_D (displacement parameters are drawn at $50 \%$ probability level).

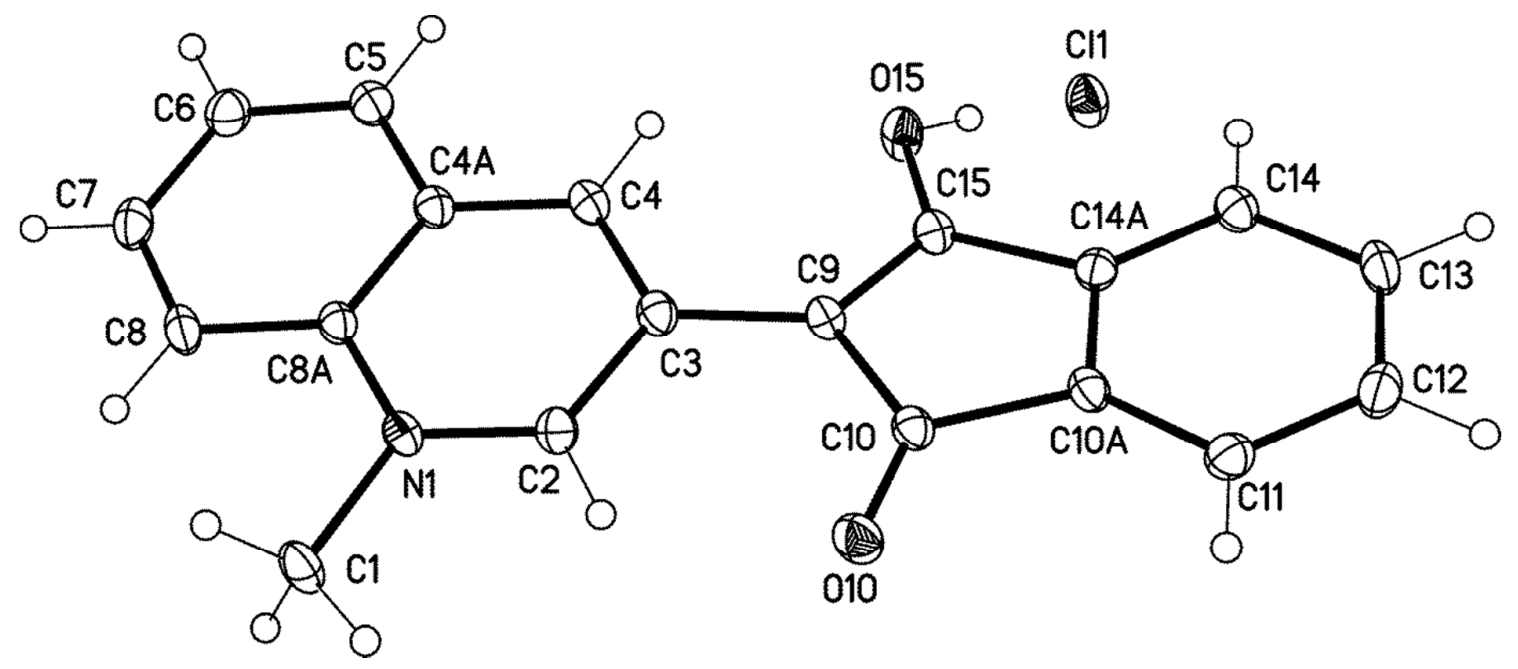

Figure S7. Molecular structure of $10+\mathrm{H}^{+}$(displacement parameters are drawn at $50 \%$ probability level). 


\section{NMR spectra}
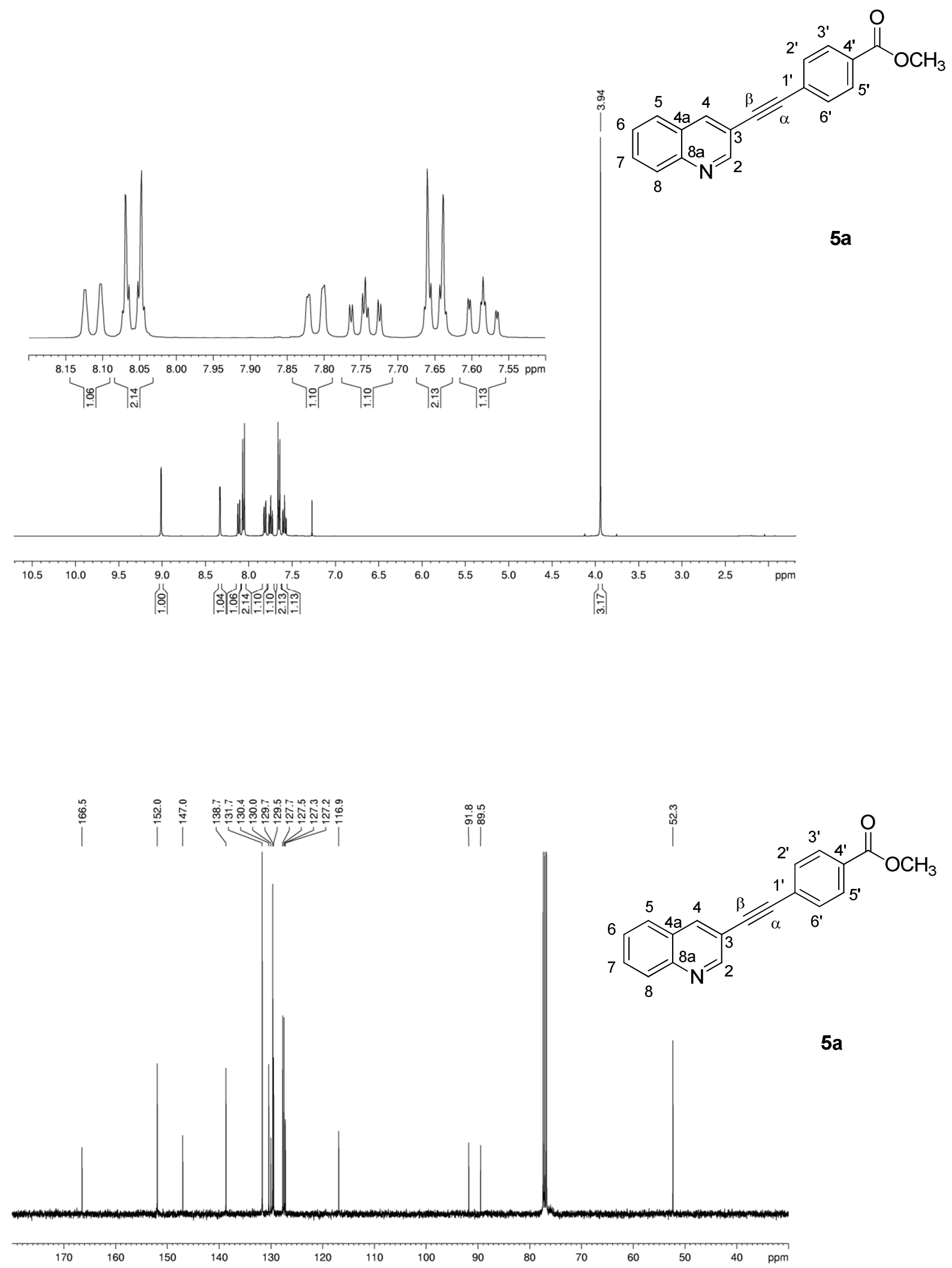

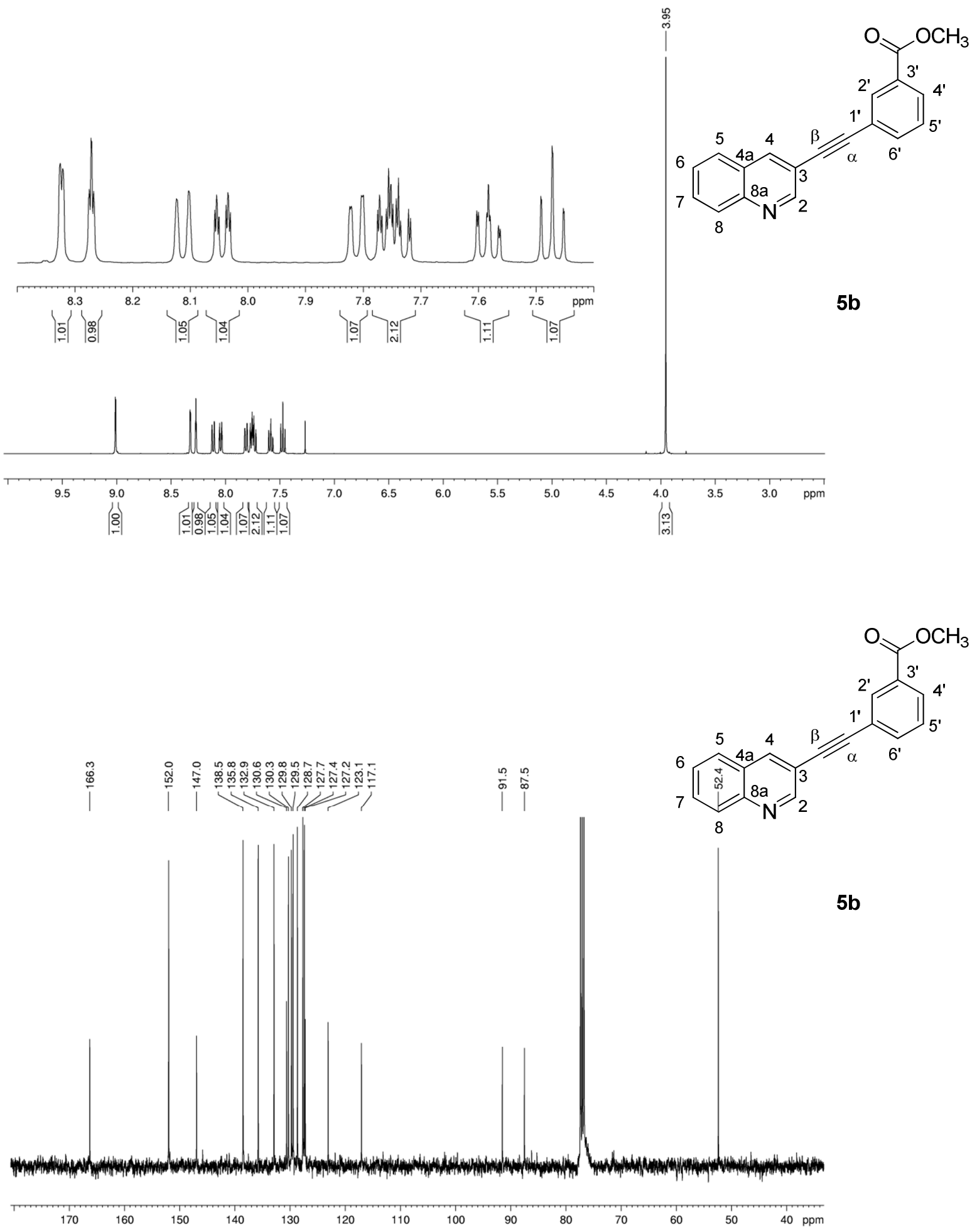

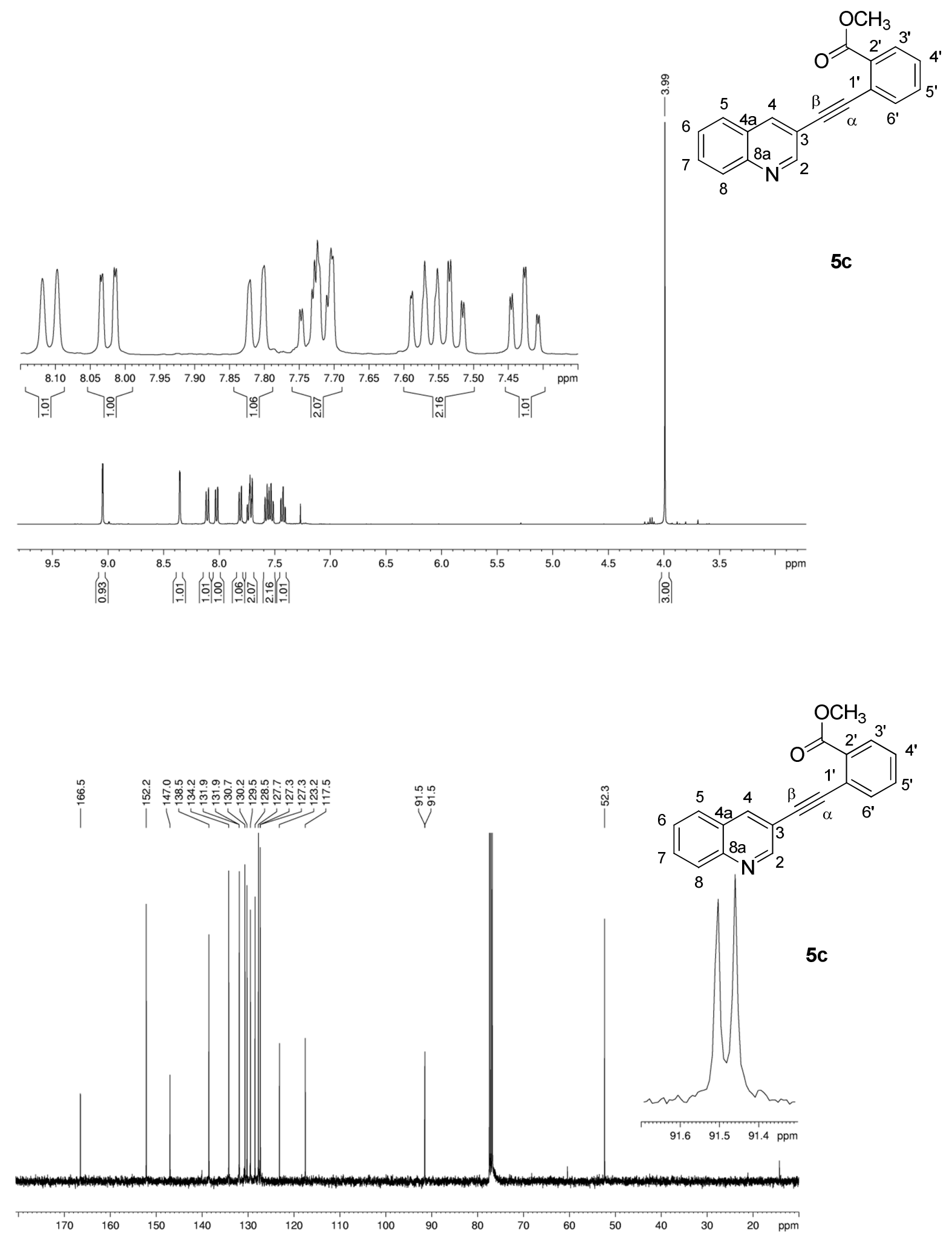
|

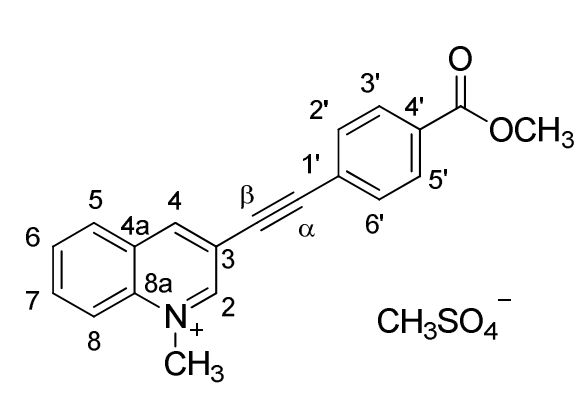

$6 \mathbf{a}$
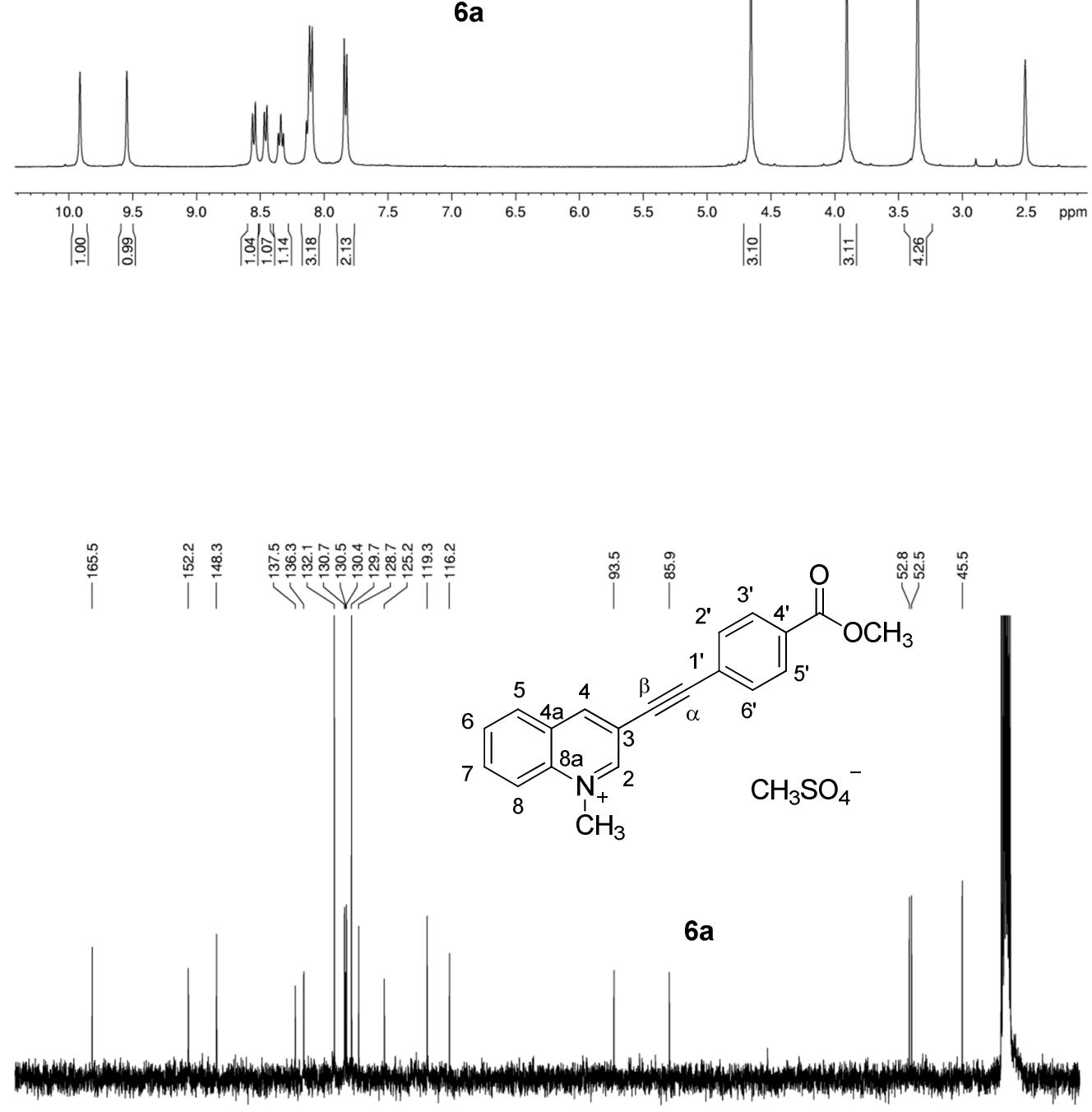

$\begin{array}{llllllllllllllllllllllllllll}170 & 165 & 160 & 155 & 150 & 145 & 140 & 135 & 130 & 125 & 120 & 115 & 110 & 105 & 100 & 95 & 90 & 85 & 80 & 75 & 70 & 65 & 60 & 55 & 50 & 45 & 40 & \mathrm{ppm}\end{array}$ 

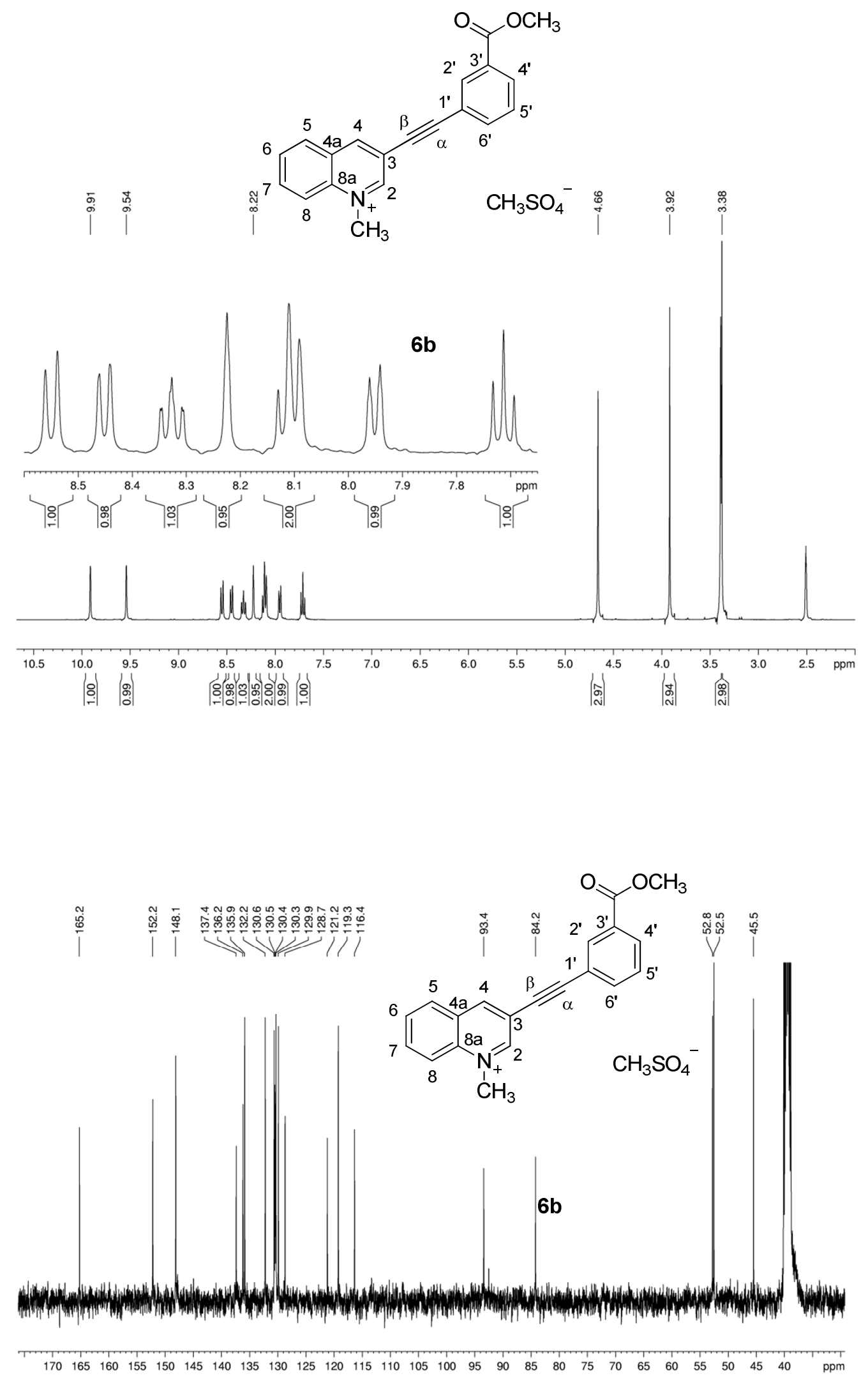

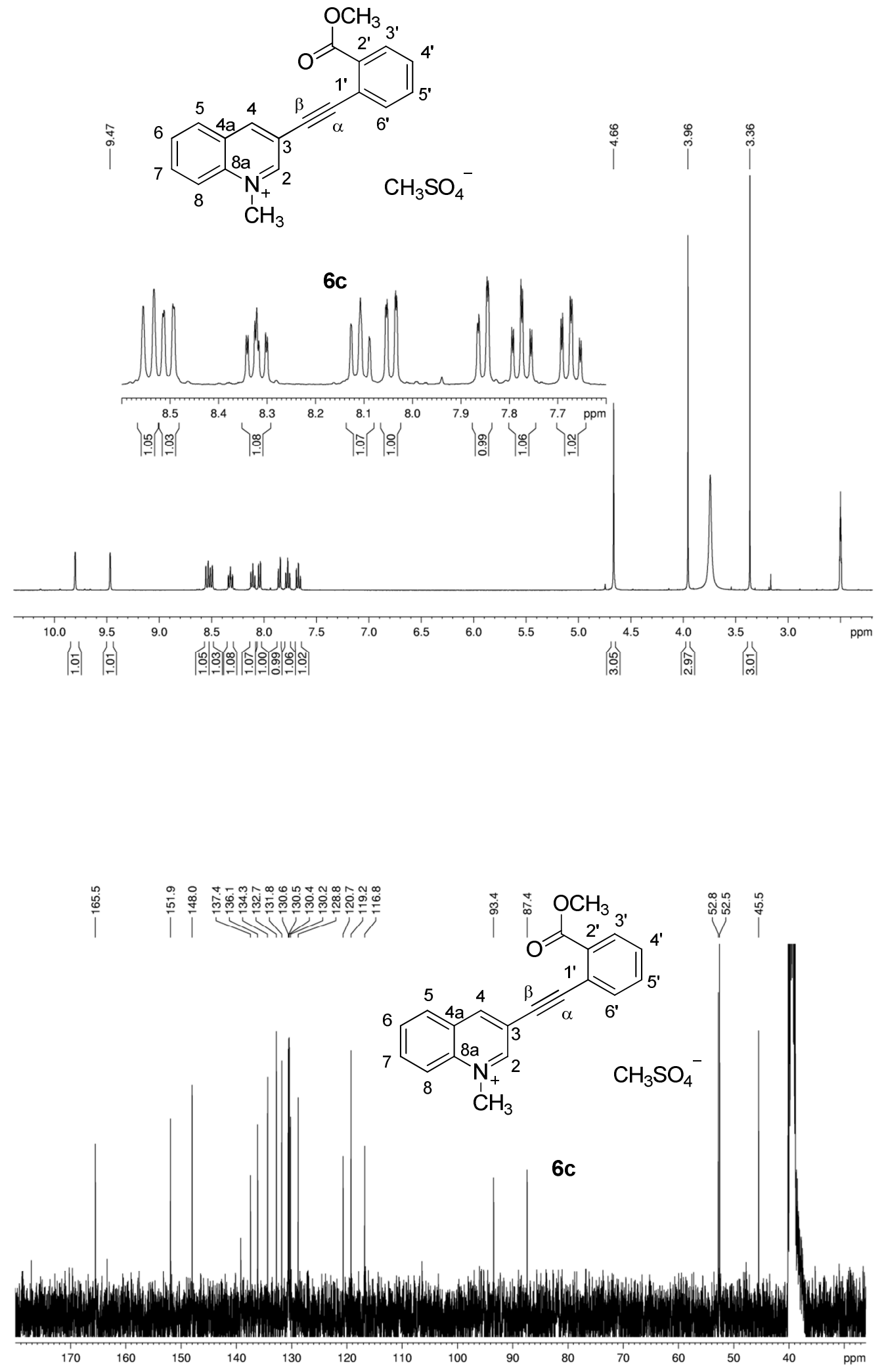

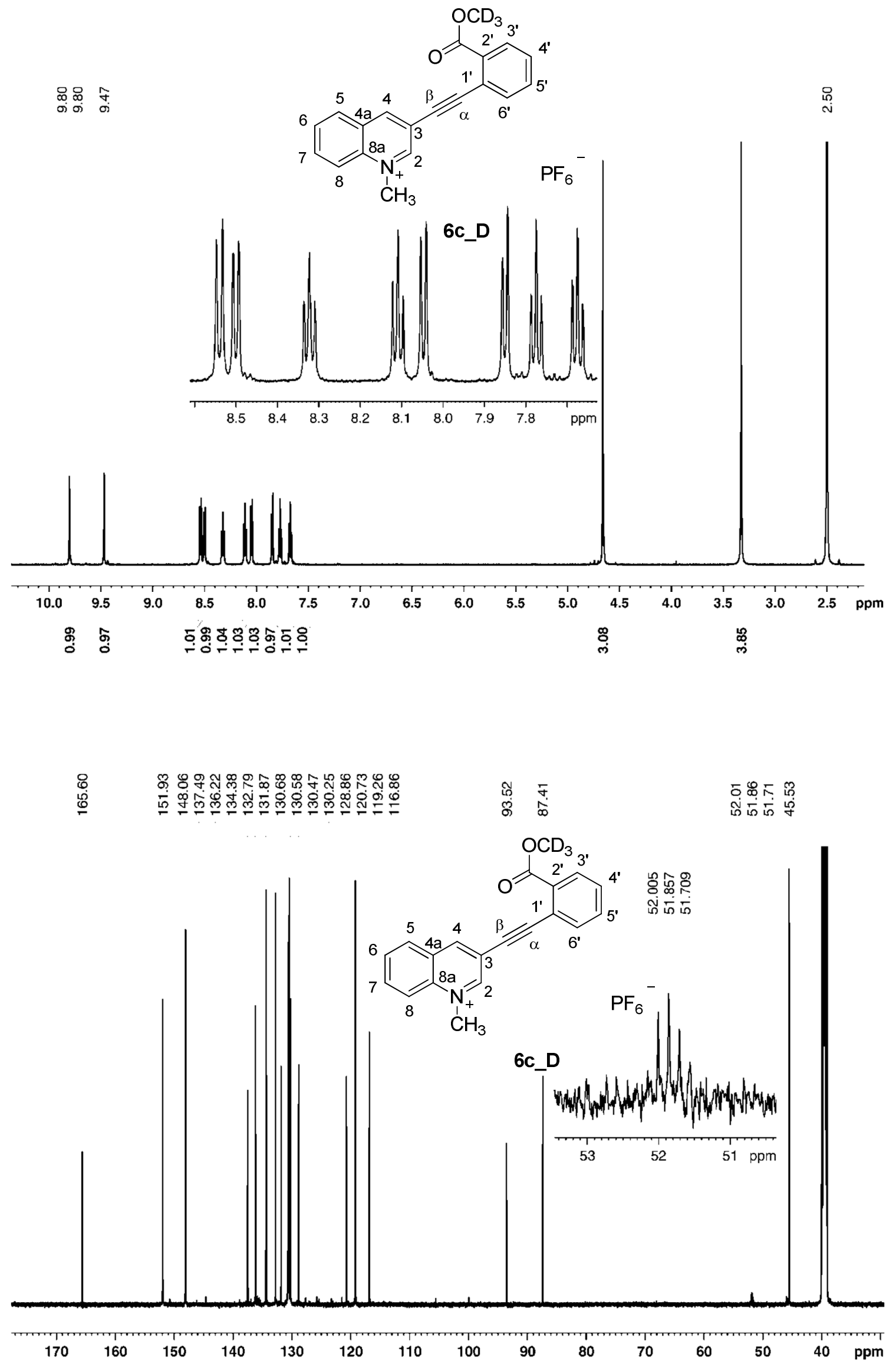


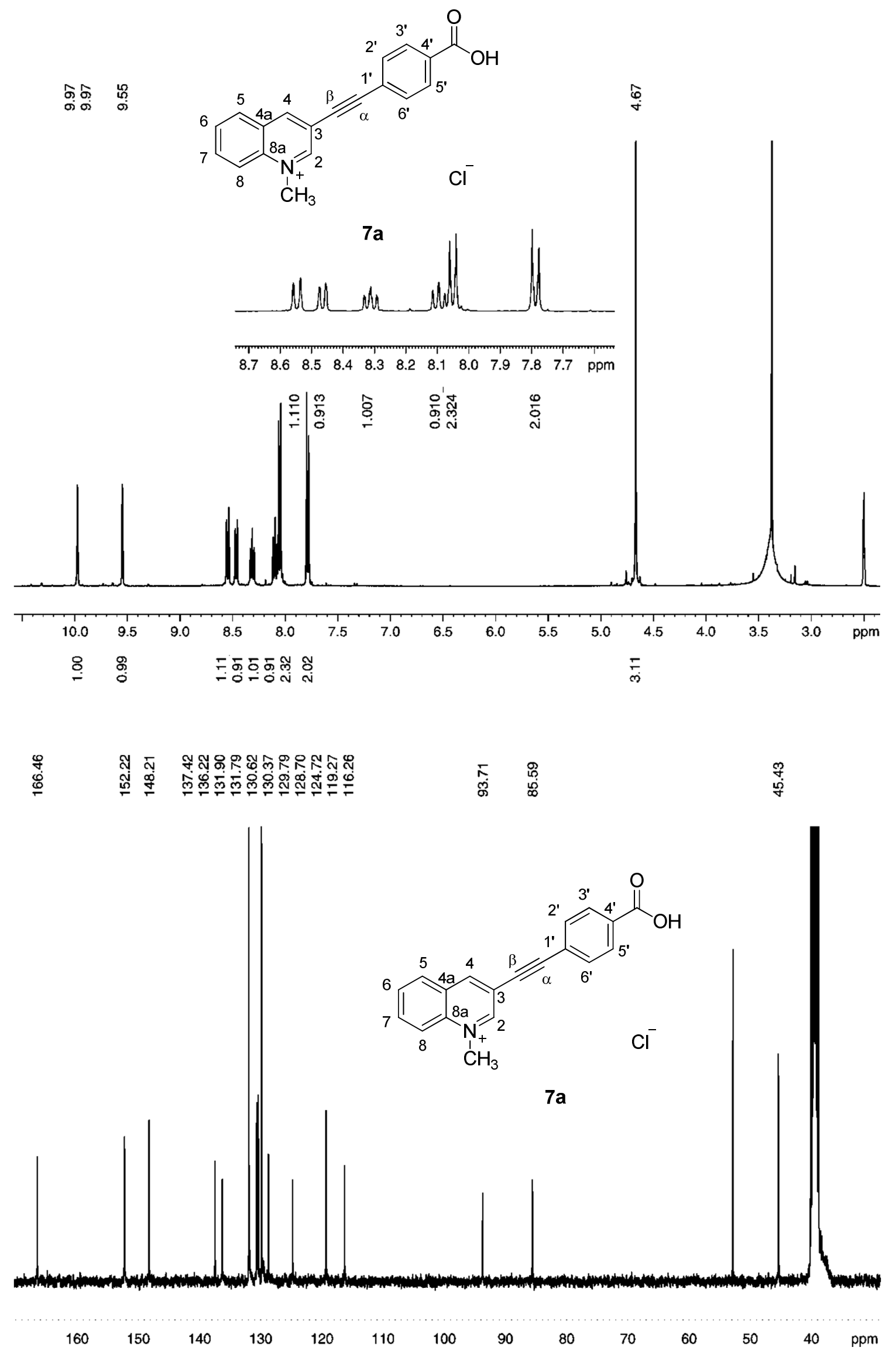




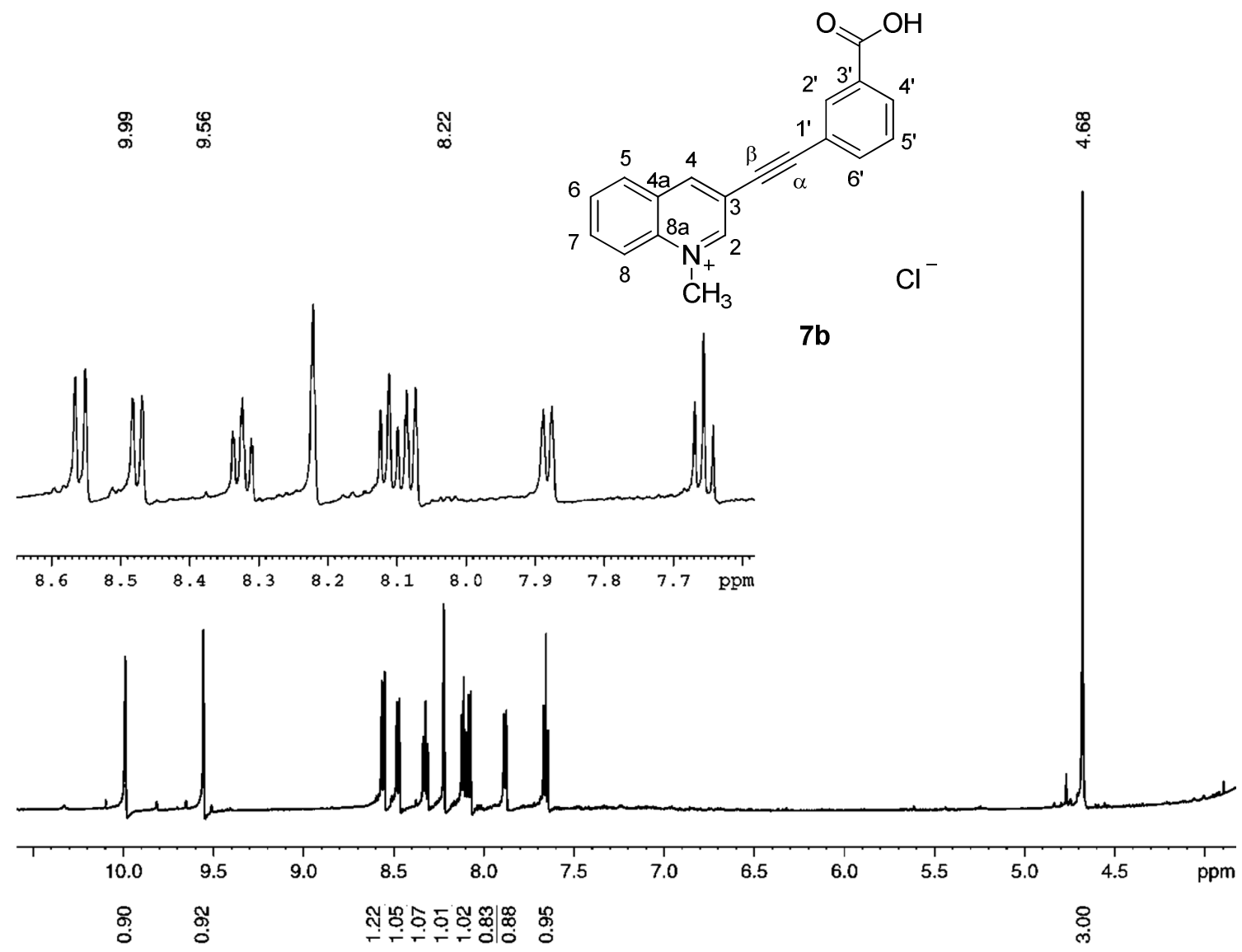

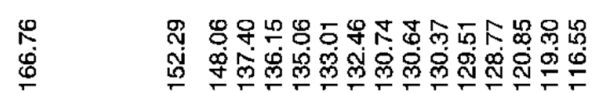

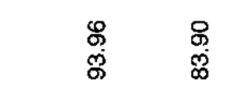

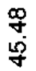

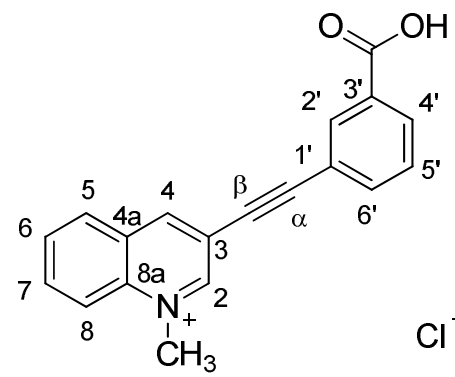

$7 b$

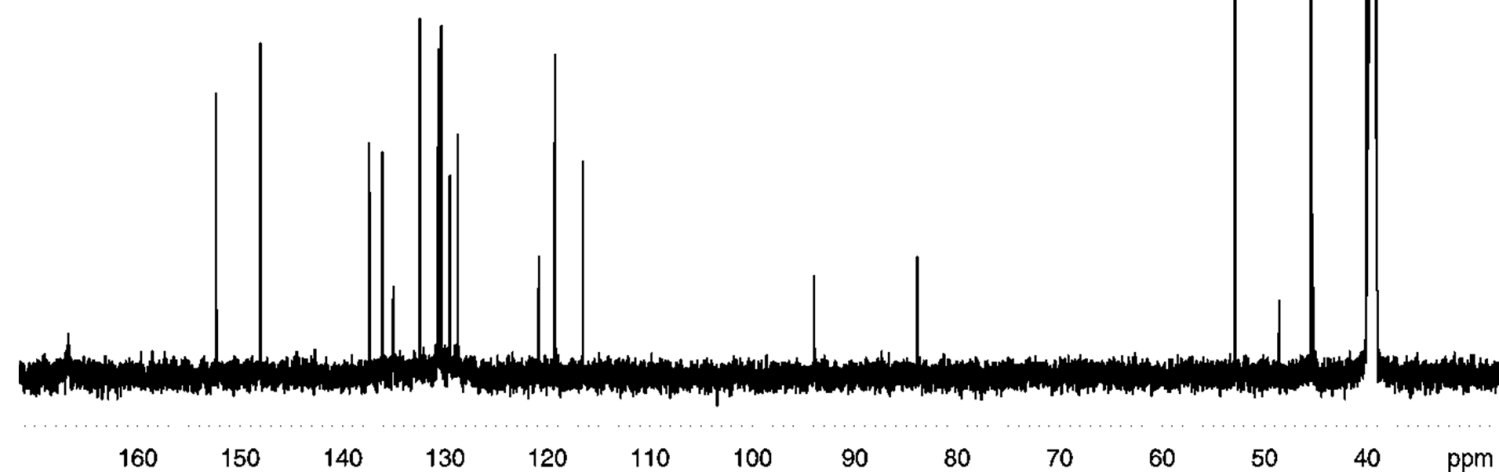



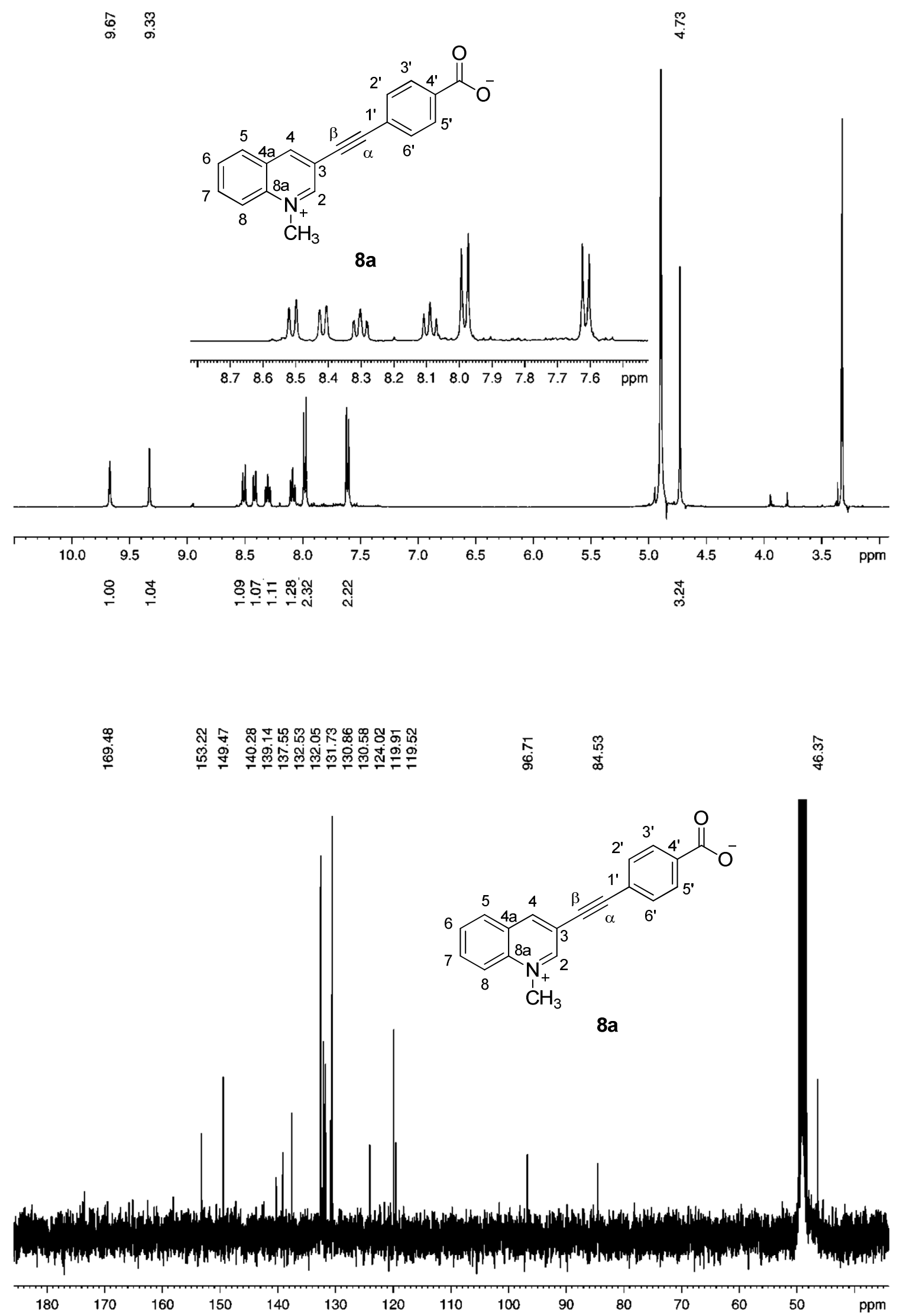


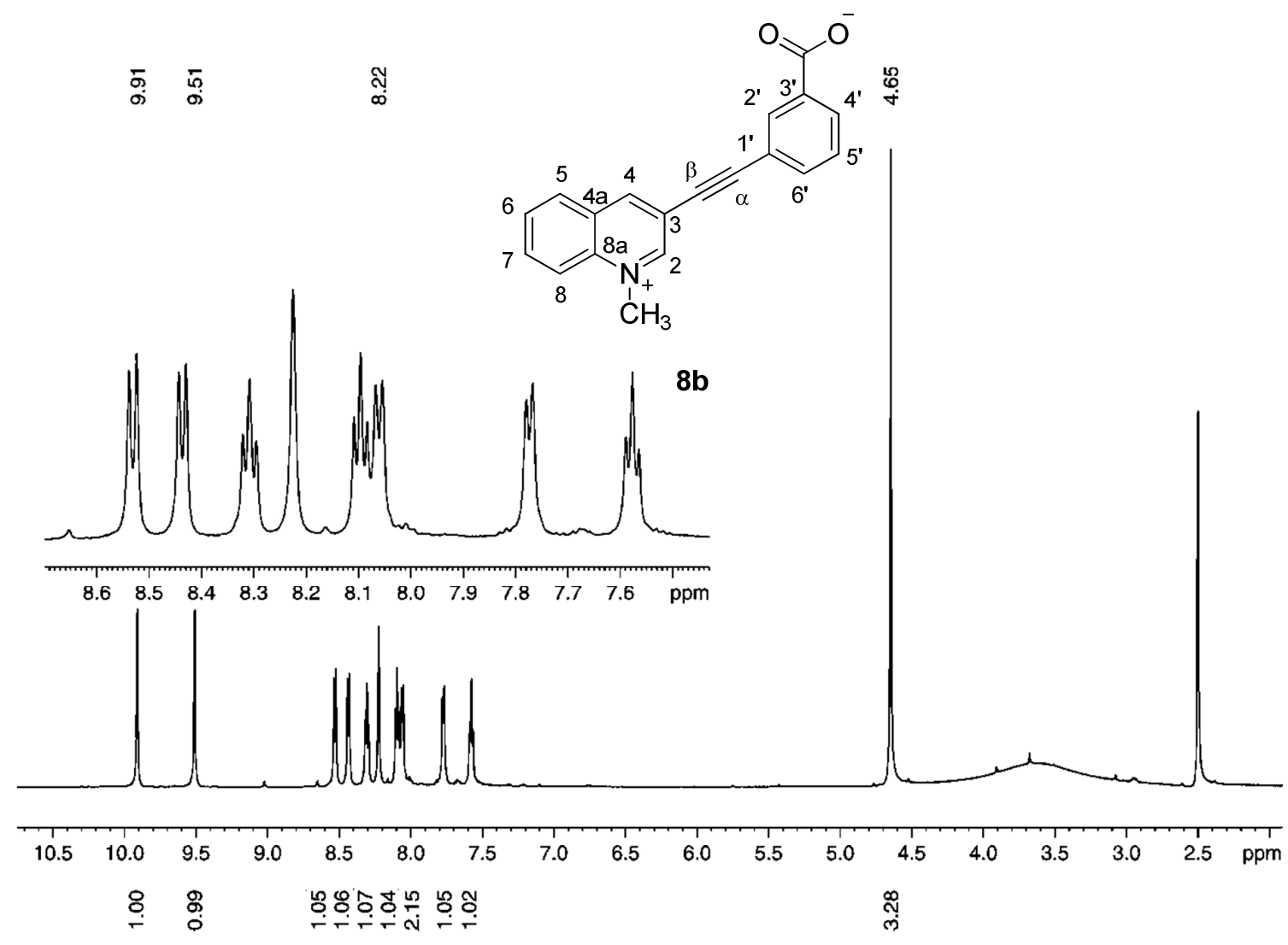

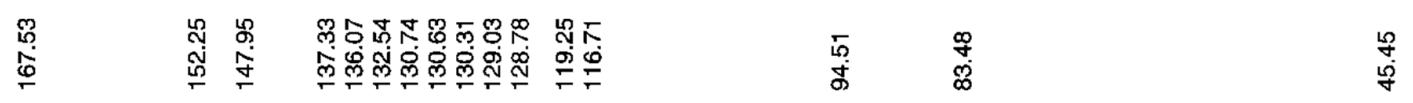

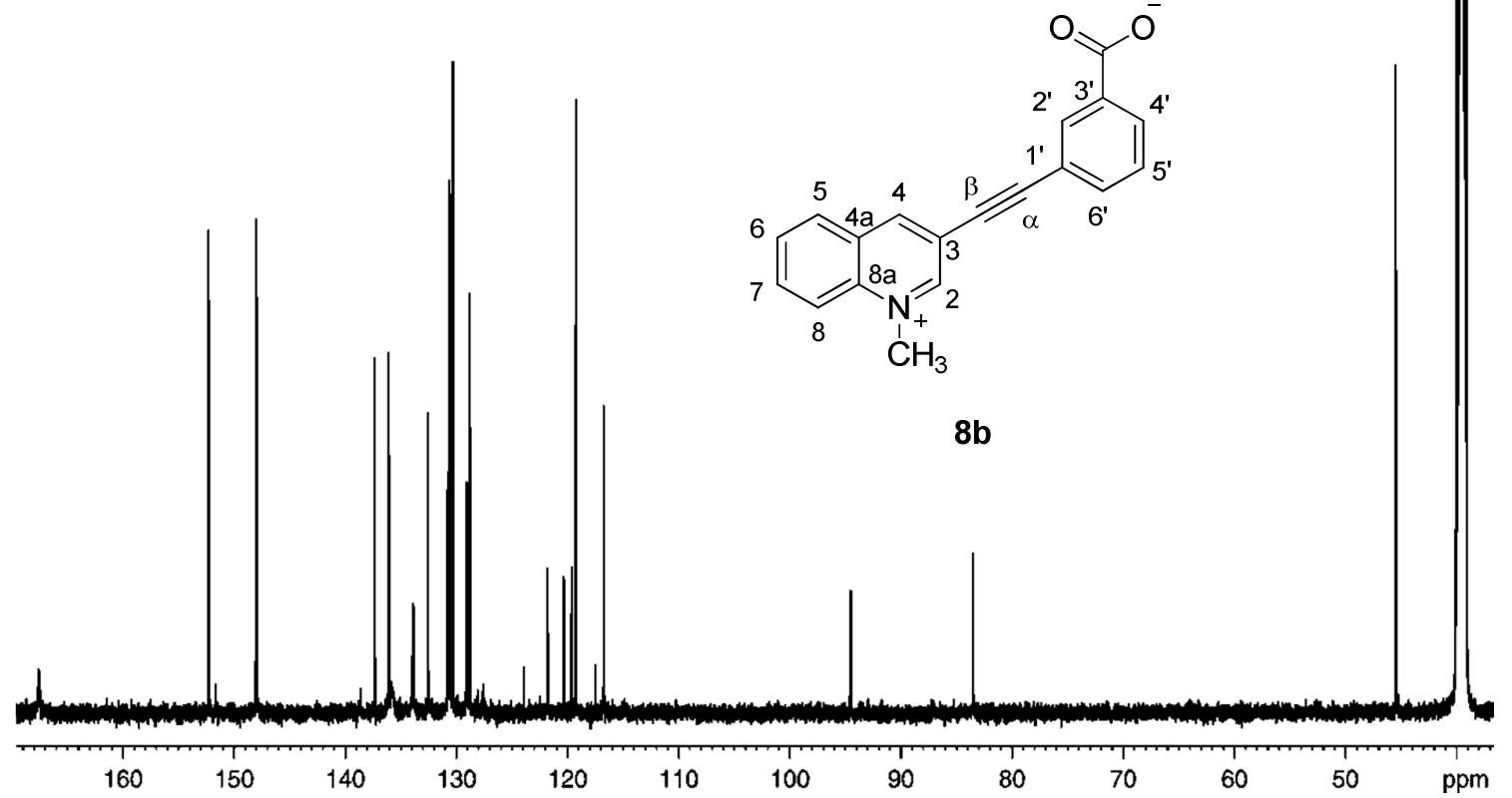




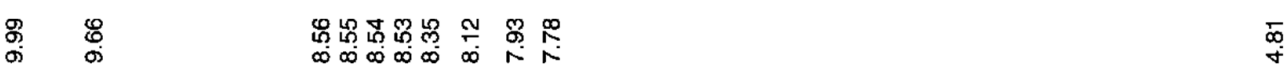
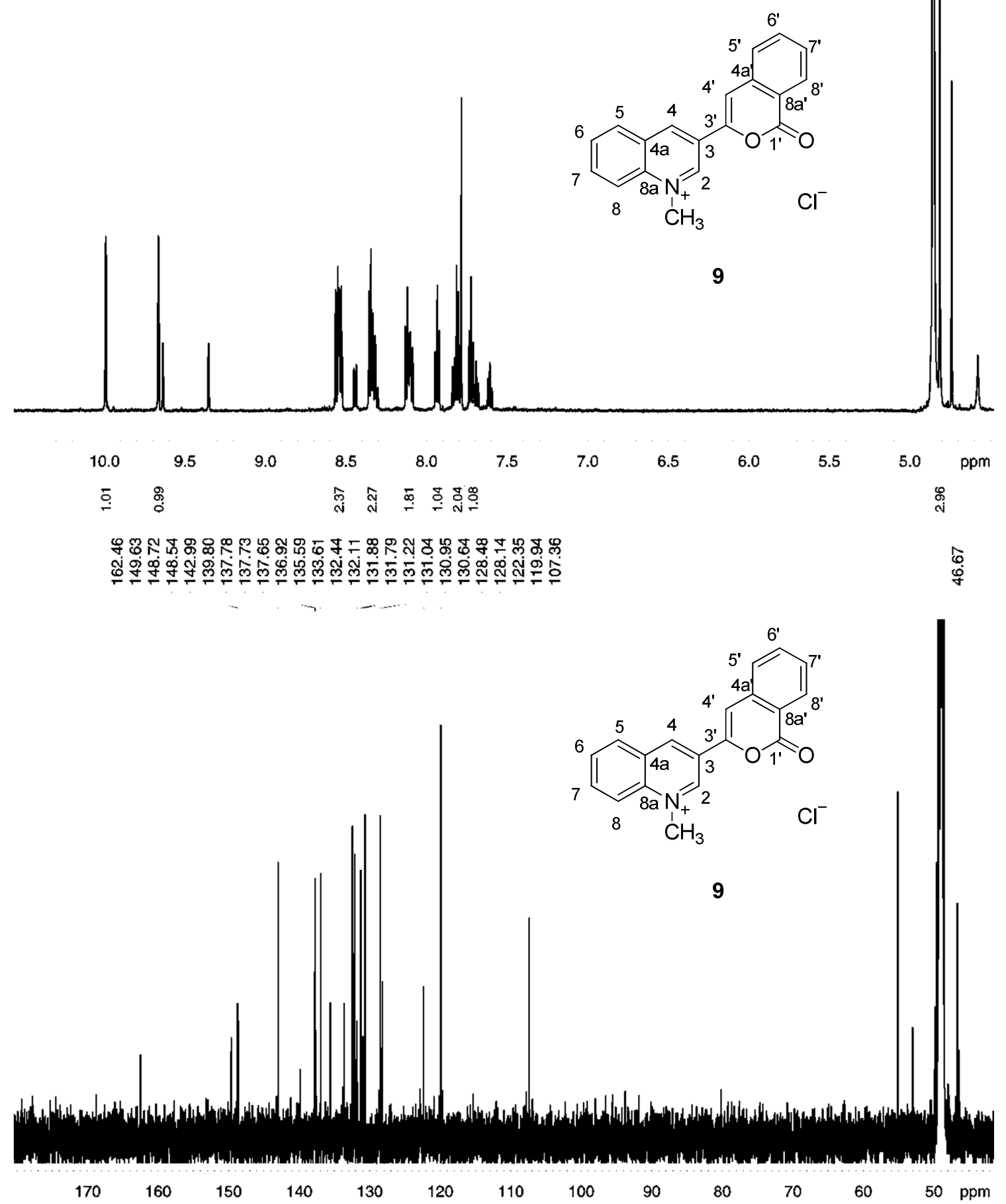


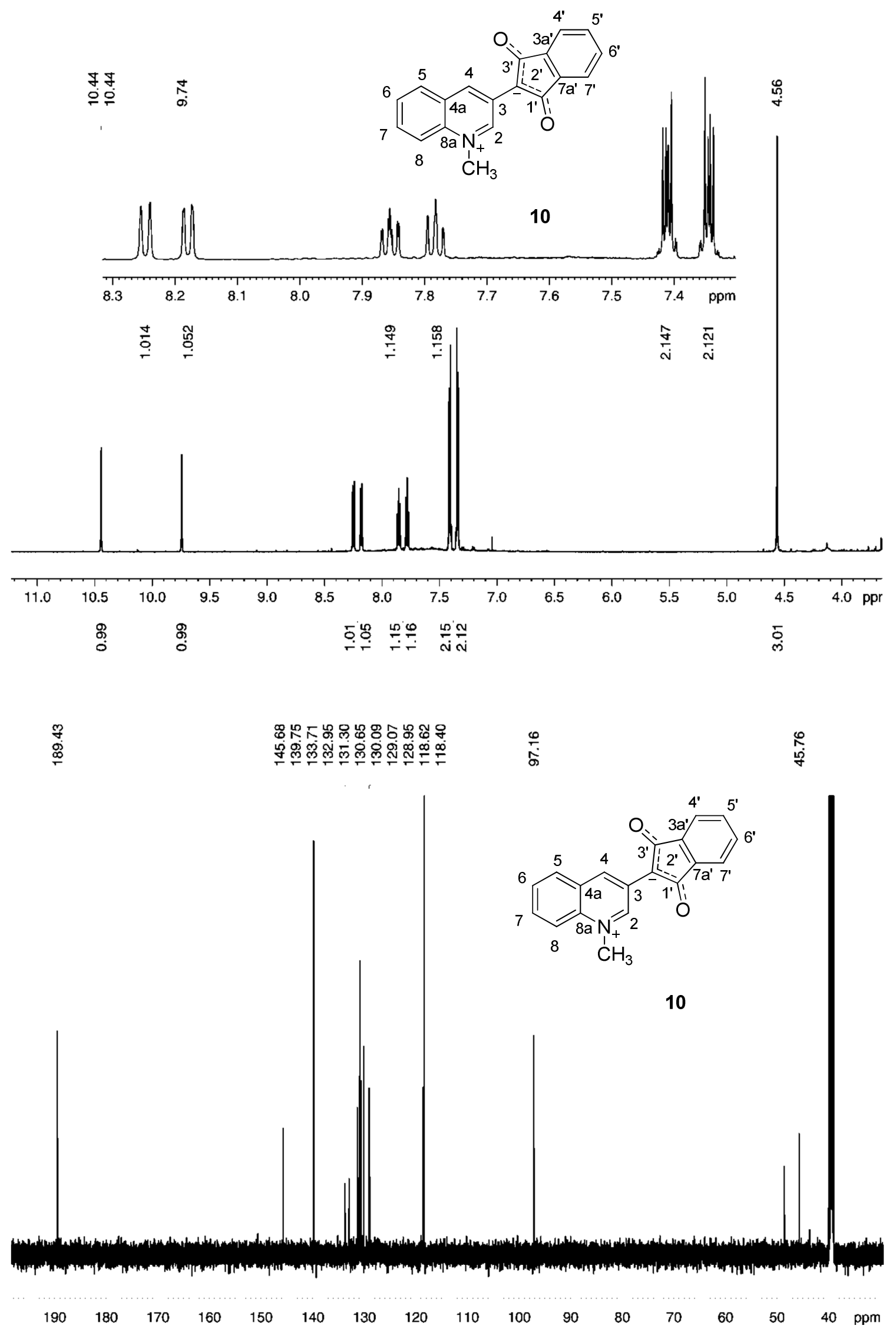



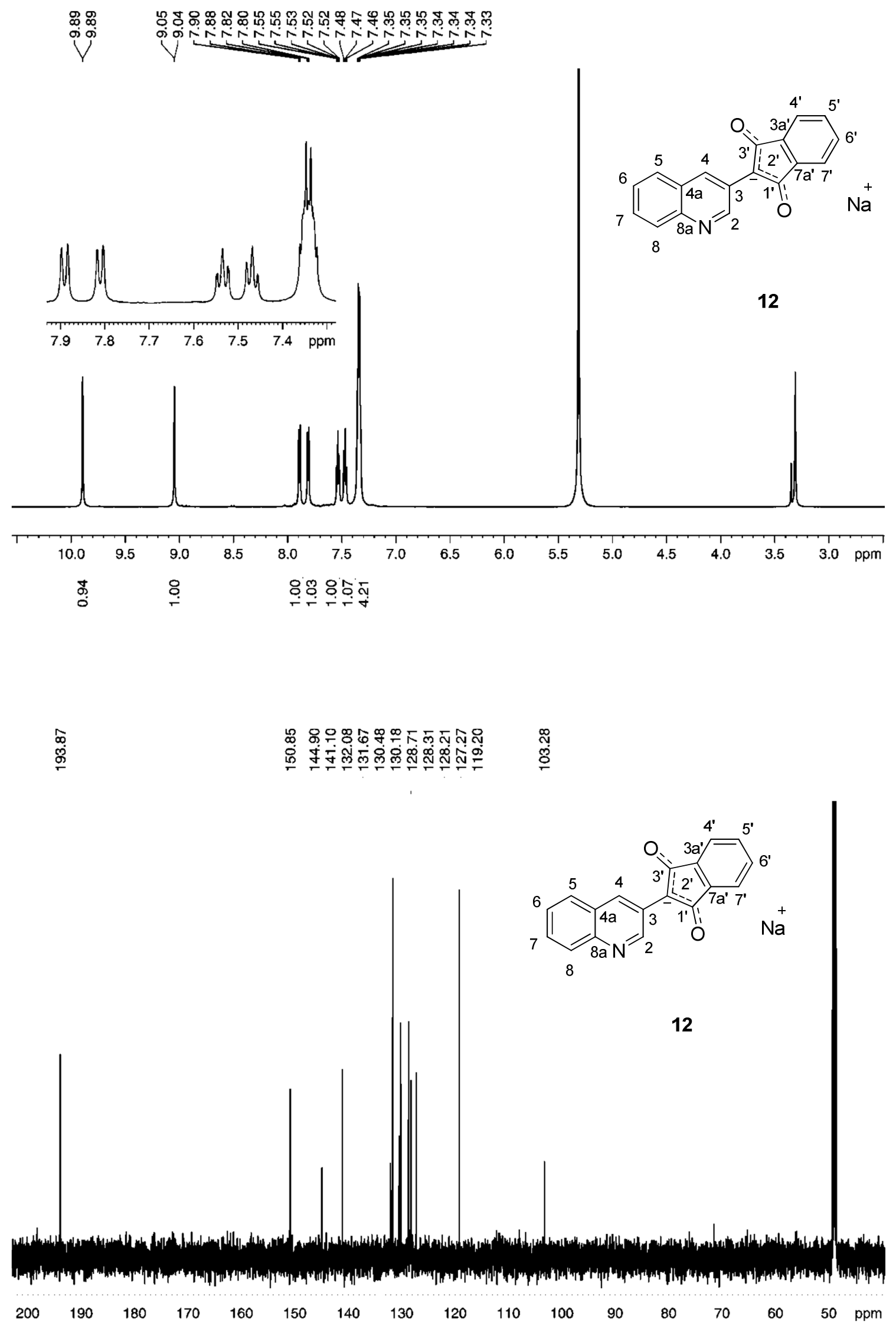


\section{Calculations.}

Structure: $\mathbf{8} \mathrm{c}_{\text {bent }}$

Number of imaginary frequencies: 0

\begin{tabular}{|c|c|c|c|}
\hline $\mathrm{C} 1$ & -6.2225832862 & -0.0075230491 & 0.2250568744 \\
\hline $\mathrm{C} 2$ & -5.8941340513 & -1.3179668501 & -0.2384055611 \\
\hline C3 & -5.1975077567 & 0.9498649522 & 0.4335640097 \\
\hline C4 & -3.8736699902 & 0.6166221388 & 0.1908660873 \\
\hline C5 & -3.5963453422 & -0.7004219593 & -0.2709330151 \\
\hline N6 & -4.5484282523 & -1.6036301142 & -0.4707382700 \\
\hline C7 & -6.9033805120 & -2.2763053855 & -0.4479096779 \\
\hline $\mathrm{C} 8$ & -8.2231209694 & -1.9437105971 & -0.2019967464 \\
\hline C9 & -8.5685921128 & -0.6554561009 & 0.2561593246 \\
\hline C10 & -7.5892106544 & 0.2907822624 & 0.4644898521 \\
\hline H11 & -5.4607590099 & 1.9425225791 & 0.7855751700 \\
\hline $\mathrm{H} 12$ & -2.5434044100 & -0.9683601943 & -0.4726301372 \\
\hline $\mathrm{H} 13$ & -6.6549027572 & -3.2704510873 & -0.7992155482 \\
\hline H14 & -8.9994024298 & -2.6852195796 & -0.3644377752 \\
\hline H15 & -9.6099000726 & -0.4119459753 & 0.4443003898 \\
\hline H16 & -7.8460898100 & 1.2855644492 & 0.8174918901 \\
\hline C17 & -1.4846618337 & 1.4817115775 & 0.2210507783 \\
\hline $\mathrm{C} 18$ & -2.7033009706 & 1.3991253860 & 0.3323941047 \\
\hline C19 & 2.6729257730 & 2.1342643749 & 0.1296221186 \\
\hline C20 & 2.1657640089 & 0.8762959879 & -0.1905132558 \\
\hline C21 & 0.7932392978 & 0.6140563154 & -0.1939581354 \\
\hline $\mathrm{C} 22$ & -0.0809659225 & 1.6758683037 & 0.1638615710 \\
\hline $\mathrm{C} 23$ & 0.4376404204 & 2.9463322700 & 0.5034469624 \\
\hline \multirow[t]{2}{*}{$\mathrm{C} 24$} & 1.8061239569 & 3.1763178470 & 0.4795844069 \\
\hline & & & \\
\hline
\end{tabular}




$\begin{array}{llll}\text { H25 } & 2.8171367063 & 0.0459566062 & -0.4435523576 \\ \text { H26 } & -0.2512476848 & 3.7378978614 & 0.7840292827 \\ \text { H27 } & 2.1969289363 & 4.1573098365 & 0.7361649414 \\ \text { H28 } & 3.7466609660 & 2.3062935625 & 0.1123915174 \\ \text { C29 } & 0.3296744960 & -0.8145933494 & -0.5776035159 \\ \text { O30 } & -0.9040472117 & -0.9426098906 & -0.8615043118 \\ \text { O31 } & 1.2149545021 & -1.6828731583 & -0.5879941321 \\ \text { C32 } & -4.1253336582 & -2.9353280746 & -0.9560848689 \\ \text { H33 } & -3.0414896044 & -2.9151293768 & -1.0789196717 \\ \text { H34 } & -4.4054164458 & -3.6994708354 & -0.2267243527 \\ \text { H35 } & -4.6033457913 & -3.1448734747 & -1.9158890876\end{array}$

Structure: $\mathbf{8 c} \mathrm{l}_{\text {inear }}$

Number of imaginary frequencies: 1

$\begin{array}{llll}\text { C1 } & -6.0121900000 & -0.3084330000 & -0.0043120000 \\ \text { C2 } & -5.5617080000 & -1.5728280000 & -0.5005980000 \\ \text { C3 } & -5.0852610000 & 0.7226570000 & 0.2653410000 \\ \text { C4 } & -3.7230620000 & 0.5131680000 & 0.0486060000 \\ \text { C5 } & -3.3274500000 & -0.7572920000 & -0.4517080000 \\ \text { N6 } & -4.1903390000 & -1.7419360000 & -0.7020570000 \\ \text { C7 } & -6.4816450000 & -2.6041310000 & -0.7686150000 \\ \text { C8 } & -7.8312480000 & -2.3920430000 & -0.5520050000 \\ \text { C9 } & -8.2965050000 & -1.1527550000 & -0.0638360000 \\ \text { C10 } & -7.4078500000 & -0.1363540000 & 0.2046020000 \\ \text { H11 } & -5.4352030000 & 1.6744220000 & 0.6508900000 \\ \text { H12 } & -2.2661940000 & -0.9390840000 & -0.6138070000 \\ & & & 21\end{array}$




\begin{tabular}{|c|c|c|c|}
\hline $\mathrm{H} 13$ & -6.1451930000 & -3.5631270000 & -1.1429420000 \\
\hline H14 & -8.5367330000 & -3.1902010000 & -0.7607410000 \\
\hline H15 & -9.3593500000 & -1.0035580000 & 0.1004940000 \\
\hline H16 & -7.7570700000 & 0.8203720000 & 0.5821290000 \\
\hline C17 & -1.6961960000 & 2.0994370000 & 0.4802060000 \\
\hline C18 & -2.6406580000 & 1.3602810000 & 0.2790930000 \\
\hline C19 & 1.5663500000 & 4.6482100000 & 1.1397170000 \\
\hline C2O & 1.7804660000 & 3.3273860000 & 0.7494480000 \\
\hline C21 & 0.7155770000 & 2.4507270000 & 0.5272950000 \\
\hline C22 & -0.6009780000 & 2.9565780000 & 0.7134220000 \\
\hline C23 & -0.8173920000 & 4.2905510000 & 1.1237240000 \\
\hline C24 & 0.2647940000 & 5.1329990000 & 1.3320520000 \\
\hline H25 & 2.7782590000 & 2.9216180000 & 0.6156400000 \\
\hline H26 & -1.8346460000 & 4.6448800000 & 1.2685930000 \\
\hline H27 & 0.1021300000 & 6.1616280000 & 1.6433660000 \\
\hline $\mathrm{H} 28$ & 2.4147290000 & 5.3090950000 & 1.3044990000 \\
\hline C29 & 1.0262660000 & 0.9768210000 & 0.1099880000 \\
\hline 030 & 0.0459070000 & 0.2763120000 & -0.2604410000 \\
\hline 031 & 2.2316510000 & 0.6654710000 & 0.1920730000 \\
\hline C32 & -3.6683330000 & -3.0312890000 & -1.1922250000 \\
\hline H33 & -2.5845340000 & -2.9586730000 & -1.2706440000 \\
\hline H34 & -3.9296710000 & -3.8258090000 & -0.4894700000 \\
\hline H35 & -4.0912420000 & -3.2512670000 & -2.1753230000 \\
\hline
\end{tabular}




$$
\begin{aligned}
& \text { Structure: } \mathbf{8} \mathbf{c}^{\prime} \text { bent } \\
& \text { Number of imaginary frequencies: } 0
\end{aligned}
$$




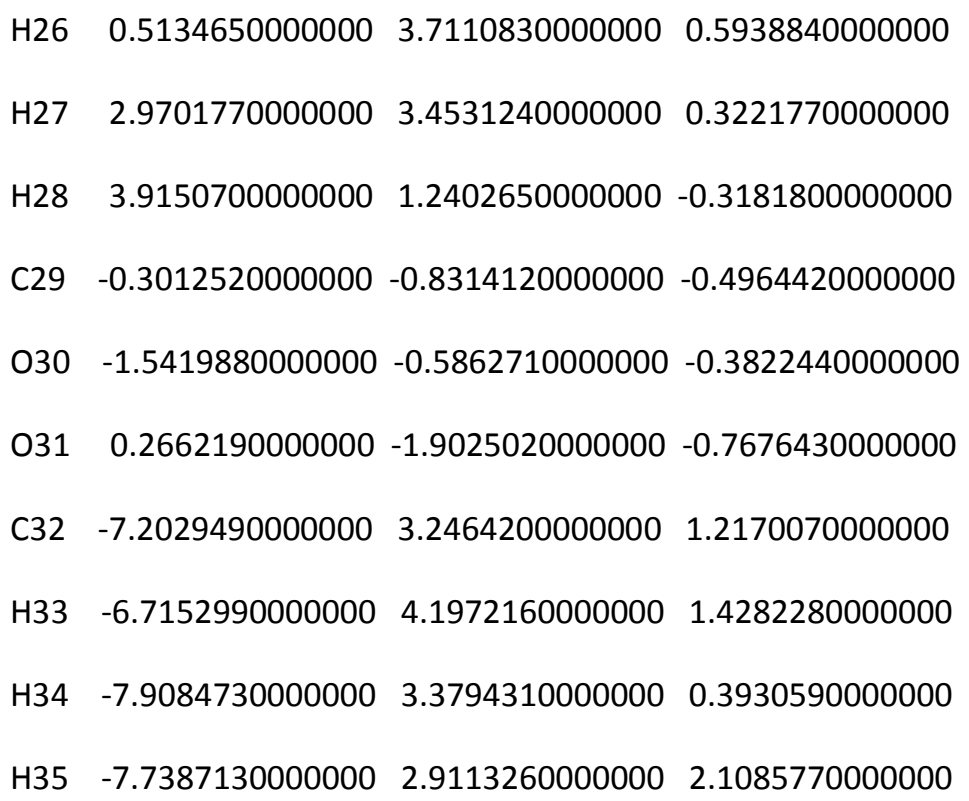

$\begin{array}{llll}\text { C1 } & -6.1834980952 & -0.0477229186 & 0.1922644561 \\ \text { C2 } & -6.3023095255 & -1.4104669965 & -0.1921088038 \\ \text { C3 } & -4.8848211743 & 0.5219993144 & 0.2597676068 \\ \text { C4 } & -3.7756892194 & -0.2384416415 & -0.0468604361 \\ \text { C5 } & -3.8518161323 & -1.6407178132 & -0.4444493315 \\ \text { N6 } & -5.1226691027 & -2.1136917310 & -0.4821502366 \\ \text { C7 } & -7.5822989594 & -1.9971893137 & -0.2672949086 \\ \text { C8 } & -8.7089519306 & -1.2481088978 & 0.0311356356 \\ \text { C9 } & -8.5996493588 & 0.1021545647 & 0.4126049711 \\ \text { C10 } & -7.3536526715 & 0.6897829678 & 0.4910266629 \\ \text { H11 } & -4.7845597945 & 1.5651041006 & 0.5544169449 \\ \text { H12 } & -7.6972143742 & -3.0338917785 & -0.5580229818 \\ \text { H13 } & -9.6887718884 & -1.7135223969 & -0.0315767655 \\ \text { H14 } & -9.4926556055 & 0.6757646111 & 0.6430227536\end{array}$




\begin{tabular}{llll} 
H15 & -7.2485804826 & 1.7315816631 & 0.7835388188 \\
C16 & -1.3626689813 & 0.8295996059 & 0.0621728156 \\
C17 & -2.4775188032 & 0.3465324481 & 0.0191001874 \\
C18 & 2.3007617104 & 2.9357029796 & 0.4833013325 \\
C19 & 2.3232279711 & 1.6392931532 & -0.0183314274 \\
C20 & 1.1449635070 & 0.9001566731 & -0.1908447408 \\
C21 & -0.1026752979 & 1.4815891544 & 0.1638229378 \\
C22 & -0.1007185951 & 2.7996213984 & 0.6728359914 \\
C23 & 1.0780708792 & 3.5172213671 & 0.8287765674 \\
H24 & 3.2588490921 & 1.1634469311 & -0.2917679541 \\
H25 & -1.0521596189 & 3.2446059524 & 0.9456861398 \\
H26 & 1.0433567614 & 4.5297981909 & 1.2223415040 \\
H27 & 3.2273988666 & 3.4894520158 & 0.6045810192 \\
C28 & 1.3282556972 & -0.4739204641 & -0.7466327163 \\
O29 & 2.4175512276 & -0.9858536932 & -0.9347981844 \\
H30 & -5.2591567964 & -3.5279826123 & -0.8744692276 \\
H31 & -4.2482388869 & -3.8881923357 & -1.0506568418 \\
H32 & -5.7318837925 & -4.1081761921 & -0.0745568215 \\
\hline & -5.8569020188 & -3.6213901403 & -1.7876645273 \\
\hline & 0.1780083108 & -1.1091622052 & -1.0403410265 \\
\hline & & -1.9889402428 & -1.3771987556 \\
\hline
\end{tabular}

